University of Nebraska - Lincoln

DigitalCommons@University of Nebraska - Lincoln

Faculty Publications: Department of

Entomology

Entomology, Department of

January 2001

Expression and induction of three family 4 cytochrome P450

(CYP4)* genes identified from insecticide-resistant and

susceptible western corn rootworms, Diabrotica virgifera virgifera

\author{
M. E. Scharf \\ New York State Agricultural Experiment Station, Cornell University, Geneva, NY \\ S. Parimi \\ University of Nebraska-Lincoln \\ Lance J. Meinke \\ University of Nebraska-Lincoln, Imeinke1@unl.edu \\ L. D. Chandler \\ University of Nebraska-Lincoln \\ Blair D. Siegfried \\ University of Nebraska-Lincoln, bsiegfried1@ufl.edu
}

Follow this and additional works at: https://digitalcommons.unl.edu/entomologyfacpub

Part of the Entomology Commons

Scharf, M. E.; Parimi, S.; Meinke, Lance J.; Chandler, L. D.; and Siegfried, Blair D., "Expression and induction of three family 4 cytochrome P450 (CYP4)* genes identified from insecticide-resistant and susceptible western corn rootworms, Diabrotica virgifera virgifera" (2001). Faculty Publications: Department of Entomology. 73.

https://digitalcommons.unl.edu/entomologyfacpub/73

This Article is brought to you for free and open access by the Entomology, Department of at DigitalCommons@University of Nebraska - Lincoln. It has been accepted for inclusion in Faculty Publications: Department of Entomology by an authorized administrator of DigitalCommons@University of Nebraska - Lincoln. 
Published in Insect Molecular Biology 10:2 (2001), pp. 139-146.

Copyright (C 2001 Blackwell Science Ltd. Used by permission. http://www.blackwell-synergy.com/loi/IMB

Submitted July 27, 2000; accepted after revisions November 7, 2000.

*Sequences are deposited in GenBank under the accession numbers AF243506, AF243507 and AF257100.

\title{
Expression and induction of three family 4 cytochrome P450 (CYP4)* genes identified from insecticide-resistant and susceptible western corn rootworms, Diabrotica virgifera virgifera
}

\author{
M. E. Scharf, ${ }^{\dagger}$ S. Parimi, L. J. Meinke, L. D. Chandler, and B. D. Siegfried \\ Department of Entomology, University of Nebraska-Lincoln, Lincoln, NE, USA \\ † Present address: Department of Entomology, New York State Agricultural Experiment Station, Cornell University, Geneva, NY 14456, USA \\ Correspondence: Prof. Blair D. Siegfried, Department of Entomology, 202 Plant Industry, University of Nebraska-Lincoln, Lincoln, NE 68583- \\ 0816, USA. Tel. (402) 472-8714; fax (402) 472-4687; email: bsiegfried1@unl.edu
}

\begin{abstract}
We have previously determined that cytochrome P450-based oxidation is involved in resistance to the insecticides methyl parathion and carbaryl in geographically distinct Nebraska western corn rootworm populations. Three new family 4 cytochrome P450 (CYP4) gene fragments (CYP4AJ1, CYP4G18 and CYP4AK1) were cloned and sequenced from insecticide-resistant and -susceptible western corn rootworms. Insecticide bioassays indicated the resistant population employed in this study was significantly resistant to the insecticides methyl parathion and carbaryl. CYP4AJ1 and CYP4G18 were cloned from both genomic PCR and RT-PCR products, although only CYP4AJ1 contains an intronic region. Alignments of inferred amino acid sequences with other homologous insect CYP4 genes indicates a high degree of similarity. Northern analysis concurrently employing mixed probes representing each of the three rootworm CYP4 fragments identified increased mRNA transcript signals (i) in resistant rootworms and (ii) following induction by the P450 inducer pentamethyl benzene. These results support our previous documentation of P450-based insecticide resistance and suggest increased CYP4 transcript abundance can serve as a molecular resistance-associated marker.
\end{abstract}

Keywords: cytochrome P450, CYP4, insecticide resistance, induction, rootworm

\section{Introduction}

Cytochrome P450 monooxygenases (P450s) are a superfamily of enzymes that occur in bacteria, fungi, plants and animals. In insects, P450s metabolize and are inducible by a diverse array of lipophilic substrates from endogenous and exogenous origins.Thus, P450s are important to many aspects of insect biology and phys- iology (Feyereisen, 1999), including insecticide resistance (Hodgson, 1985; Scott, 1999). With this diversity in function, it would be expected that multiple P450 forms should occur in insects. Approximately 100 insect P450s had been classified into six CYP families 4, 6, 9, 12 and 28 (Feyereisen, 1999). With particular regard to the CYP4 family, a wide spectrum of genes were initially found in a number of insect groups, including Anopheles (Scott et al., 1994), Manduca (Snyder et al., 1995), Drosophila (Dunkov et al., 1996) and Helicoverpa (Pittendrigh et al., 1997). Interestingly, the recently completed Drosophila genome sequencing project tentatively identified eighty-six functional CYP genes and four pseudogenes, with over $50 \%$ being classified as either CYP4 or CYP6 (Adams et al., 2000).

Insect P450 proteins are expressed at low levels and can be quite labile, therefore molecular approaches provide a viable alternative for the study of insect P450 diversity and the isolation individual forms (Feyereisen, 1999). However, with the existence of such P450 diversity as noted above, the identification of specific forms important to insecticide resistance can be challenging (Scott, 1999). Aside from direct metabolism by heterologously expressed CYP cDNAs (Andersen et al., 1994; Dunkov et al., 1997; Smith \& Scott, 1997), strong evidence supporting the involvement of a P450 in insecticide resistance is the increased abundance of its gene transcript in resistant insect strains (e.g. Cariño et al., 1994; Liu \& Scott, 1998; Pittendrigh et al., 1997; Kasai et al., 2000). However, the possibility that other as yet unidentified modifications exist should not be overlooked (i.e. point mutations resulting in increased cat- 
alytic activity; Scott, 1999). Recent efforts using PCRbased homology probing (Snyder et al., 1996) have provided insight into insect P450 diversity and have enabled researchers to compare expression levels for individual forms and test hypotheses of P450-mediated insecticide resistance. With this approach, degenerate P450 primers are used to isolate P450 gene fragments, which are then used as templates for the synthesis of northern blot probes that enable the comparison of P450 transcript levels [e.g. CYP4G8 (Pittendrigh et al., 1997) and CYP6F1 (Kasai et al., 2000) ].

The western corn rootworm, Diabrotica virgifera virgifera L., is one of the most significant economic pests of field corn, Zea mays L., in the USA, and for this reason is heavily targeted by insecticide applications (Levine \& Oloumi-Sadeghi, 1991). In the state of Nebraska, largescale continuous corn production and uniform insecticide selection pressures led to the development of widespread resistance to the cyclodienes in the late 1950s (reviewed by Metcalf, 1983) and to organphosphates and carbamates in the early 1990s (Meinke et al., 1998). Physiological mechanisms involved in the most recent resistance occurrence have been extensively studied and include an interaction of oxidative (i.e. P450-based) and hydrolytic (i.e. esterase-based) insecticide metabolism (Miota et al., 1998; Scharf et al., 1999a,b). Specific resistance-associated conversions catalysed by $\mathrm{P} 450$ include oxidation and $\mathrm{N}$-demethylation, respectively, of organophosphate (Miota et al., 1998) and carbamate (Scharf et al., 1999b, 2000b) insecticides. Two additional xenobiotic conversions not associated with detoxification are also mediated by P450 in this species: sulfoxidation of the phenylpyrazole insecticide fipronil (Scharf \& Siegfried, 1999; Scharf et al., 2000a), and epoxidation of the cyclodiene insecticide aldrin (Siegfried \& Mullin, 1990).

Induction of P450 proteins is associated at the molecular level with the increased abundance of CYP gene transcripts (Nebert \& Gonzalez, 1987). The elevated presence of rootworm haemoproteins in the 45-60 kDa molecular mass range (Scharf et al., 2000b), in association with metabolism data, provide reasonable evidence to support that over-expression of CYP gene transcripts is occurring in resistant populations. In induction experiments, ingestion of the P450 inducer pentamethyl benzene enhanced $\mathrm{N}$-demethylation activity and haemoprotein content most substantially in more susceptible rootworm populations (Scharf et al., 2000b). These results prompted us to hypothesize that differences in P450 regulation may exist between resistant and susceptible individuals.

Although a biochemical understanding of western corn rootworm P450 is emerging, nothing is presently known of the specific P450 forms involved in insecticide metabolism nor any other aspect of rootworm physiology. To begin to develop this understanding and to identify potential resistance-associated markers, we set out to investigate rootworm P450 at the molecular level. Information on the catalytic specificity of various P450 families is presently limited, however we chose to focus on family 4 because of the number of forms previously isolated using a degenerate-PCR approach (Snyder et al., 1996). Here, we report results of our efforts using degenerate CYP4 primers to isolate three gene fragments from insecticide resistant and susceptible western corn rootworm populations and to test hypotheses of increased transcript abundance as a molecular marker for insecticide resistance. The specific objectives of this study were to: (i) sample CYP4 gene diversity, and (ii) to investigate potential differences in transcript expression levels that might be associated with insecticide resistance and induction.

\section{Results}

\section{Bioassays}

Diagnostic concentration bioassays were conducted to confirm the resistance- and susceptibility-status of these populations as earlier characterized from collections in previous years. Relative to the susceptible Saunders population (100\% mortality), significant $(P \leq 0.01)$ levels of resistance were present in the York population to the insecticides methyl parathion (19.4\% mortality) and carbaryl (69.0\% mortality). Percentage survival on these diagnostic concentrations corresponds approximately to the percentage of the York population, which exceeds the susceptible $\mathrm{LC}_{99}$ for methyl parathion $(80.6 \%)$ and carbaryl (31.0\%).Thus, while the York population clearly possess increased survivorship on insecticide residues, it is not homogeneous for resistance (i.e. significant portions of the population remains susceptible).

\section{CYP4 gene fragments amplified by PCR and RT-PCR}

Three previously undescribed CYP4 gene fragments were successfully cloned and have been named $C Y$ P4AJ1, CYP4G18 and CYP4AK1 (accession numbers AF243507, AF243506 and AF257100). The three CYP4 fragments amplified and cloned from first strand cDNA by RT-PCR range from 444 to 453 nucleotides and encode peptides ranging in size from 148 to 151 amino acids. Sixty-five per cent of clones were successfully sequenced (twenty of thirty-one), and only the three CYP4 sequences were found. None of the three gene fragments were successfully cloned following RT-PCR amplification of susceptible 1st strand CDNA, and only CYP4AK1 was cloned and sequenced from resistant 1st strand cDNA (Table 1).

CYP4AJ1 and CYP4G18 were amplified and cloned from both genomic and 1st strand cDNA templates of resistant and susceptible populations (Table 1). Based on alignment of genomic and CDNA sequences, only the genomic CYP4AJ1 fragment contains an intronic region (Fig. 1).This intron is sixty-three nucleotides in length, and possesses two highly conserved features of eukaryotic 
Table 1. Number of clones found encoding various $D$. v. virgifera CYP4 fragments following PCR amplification of genomic DNA and reverse-transcribed 1 st strand cDNA from insecticide-resistant and susceptible populations

\begin{tabular}{lllll}
\hline $\begin{array}{l}\text { D. v. virgifera } \\
\text { CYP fragment }\end{array}$ & $\begin{array}{l}\text { Resistant } \\
\text { genomic }\end{array}$ & $\begin{array}{l}\text { Susceptible } \\
\text { genomic }\end{array}$ & $\begin{array}{l}\text { Resistant } \\
\text { cDNA }\end{array}$ & $\begin{array}{l}\text { Susceptible } \\
\text { cDNA }\end{array}$ \\
\hline CYP4AJ1 & 5 & 5 & 2 & 0 \\
CYP4G18 & 0 & 5 & 1 & 0 \\
CYP4AK1 & 0 & 0 & 2 & 0 \\
No. Sequenced & 10 & 10 & 6 & 5 \\
\hline
\end{tabular}

introns: (i) 5'-GT and $3^{\prime}-A G$ splice junctions and (ii) the presence of a termination codon (TAA; Fig.1). Relative to other insect CYP4 introns, the CYP4AJ1 intron is smaller in size and approximately 150 nucleotides upstream of introns reported for $A$. albimanus (Scott et al., 1994) and H. armigera (Pittendrigh et al., 1997).

Excluding priming regions, nucleotide similarity is 50 $51 \%$ with only $35-40 \%$ amino acid identity between the three rootworm CYP4 fragments (Table 2A). Based on this moderate degree of sequence similarity, it is unlikely that any of the three sequence variants represent alleles of the same gene. No sequence variants were obtained to suggest potential allelic variation-associated polymorphisms. Nonetheless, these gene fragments clearly represent portions of CYP4 genes based on the presence of highly conserved distances between the CYP4 primers used (123-126 amino acids), and the invariability of P450 signature motifs 'ETLR' and 'PDNF/PERF' in the three translated peptides (Fig. 2).

A BLASTx search of GenBank using the three rootworm CYP4 nucleotide sequences (excluding priming regions) identified three insect CYP4 genes that shared optimal homology to the three rootworm CYP4 fragments
(Table 2B): Diploptera punctata (Blattaria: Blaberidae) CYP4C4 (48 and 47\% identical to CYP4AJ1 and CY$P 4 A K 1$, respectively); Trichogramma cocoeciae (Hymenoptera: Trichogrammatidae) CYP4G12 (76\% identical to CYP4G18); and Helicoverpa armigera (Lepidoptera: Noctuidae) CYP4G8 (73\% identical to CYP4G18). Alignments of the inferred amino acid sequences (excluding priming regions) for these six CYP4 gene fragments indicates the presence of twenty-two invariant residues and a high degree of overall similarity (Fig. 2). Based on their $35-40 \%$ amino acid identity (see above) and phylogenetic analysis that places them on separate branches (Fig. 3), it is likely that the three rootworm CYP4 genes are members of different CYP4 subfamilies. As can be seen by the dendrogram in Fig. 3, CYP4 members from several insect groups share a great deal in common with the three rootworm CYP4 fragments. Interestingly, the closest Drosophila homologue was CYP4G1, which clusters closest to the rootworm CYP4AK1, yet shares higher identity to CYP4G18 (65\%).

\section{Determination of CYP4 expression levels}

Northern blotting experiments employed a mixed probe representing each of the three rootworm CYP4 fragments. This approach facilitated the collective assessment of expression levels and PMB-induction of transcripts encoded by the three rootworm CYP4 genes. mRNA ( $1 \mu \mathrm{g}$ per lane) was isolated from abdomens of resistant and susceptible beetles, which had ingested either corn or the P450-inducer PMB in water. A single $1.84 \mathrm{~kb}$ mRNA band hybridized with the mixed probe (Fig. 4). Constitutive signals in corn-fed beetles were 1.6-fold more intense for resistant relative to susceptible transcripts. Following PMB-induction, signal intensity

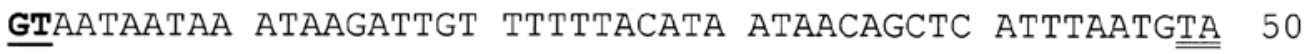

ATCTTATTTT A

Figure 1. Nucleotide sequence for 63 bp intron, which occurs in the genomic CYP4AJ1 sequence at the site indicated in Figure 4. The 5'-GT and 3'AG intron splice junctions are bold and single underlined, and a putative termination codon common to eukaryotic introns is double-underscored.

Table 2. Per cent identity and per cent similarity (in parentheses) among three rootworm CYP4 fragments and with other CYP4 genes from D. punctata, H. armigera and T. cacoeciae. (A) Deduced amino acid sequences are compared in upper right diagonal and nucleotide sequences are compared in the lower left diagonal. (B) Per cent identities of three rootworm CYP4 fragments to homologous CYP4 fragments from other insect species at the amino acid level

\begin{tabular}{|c|c|c|c|c|c|c|}
\hline & \multicolumn{3}{|l|}{$A^{*}$} & \multicolumn{3}{|l|}{$\mathrm{B} \dagger$} \\
\hline & CYP4AJ1 & CYP4G18 & CYP4AK1 & D. punctata CYP4C4 & H. armigera CYP4G8 & T. cacoeciae CYP4G12 \\
\hline CYP4G18 & 51 & - & $40(54)$ & $<40$ & 73 & 76 \\
\hline CYP4AK1 & 50 & 50 & - & 47 & $<40$ & $<40$ \\
\hline
\end{tabular}

*Analyses were performed using the 'GAP' function in GCG10. See text for details

†Analysis preformed by BLASTx in GenBank. Values indicated in bold type represent the highest percentage identities found. 

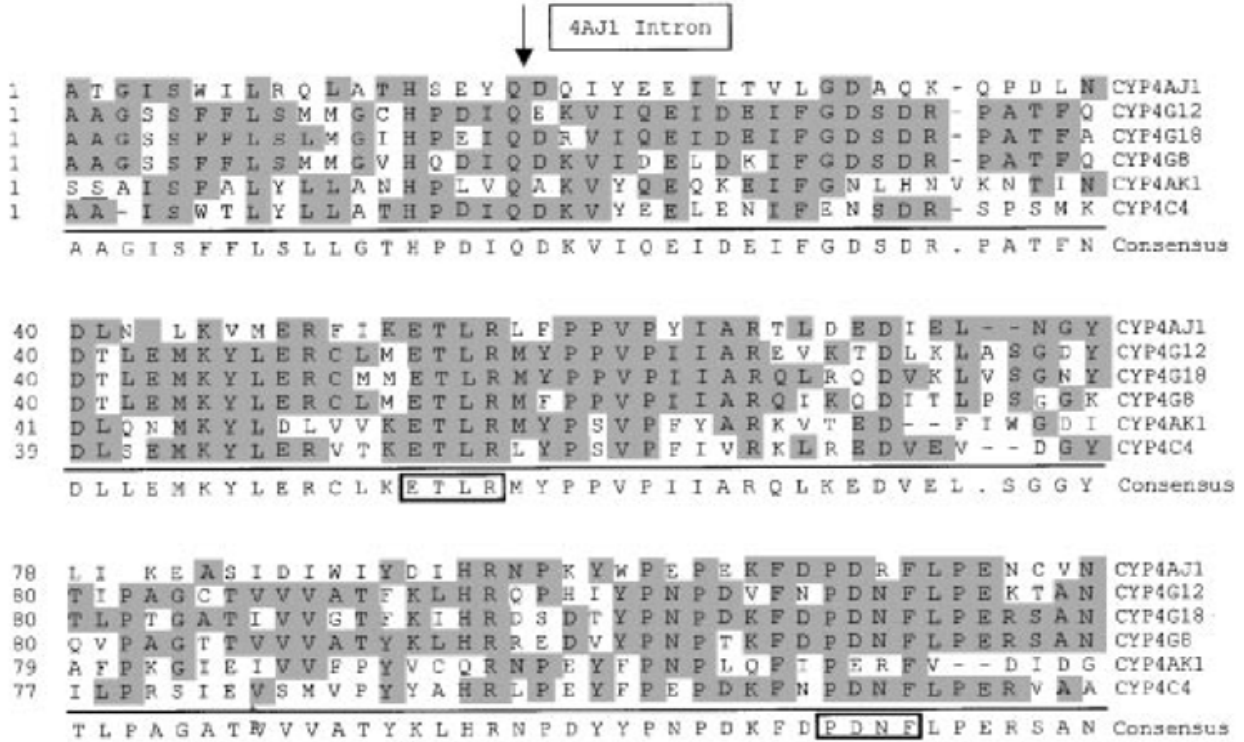

Figure 2. Alignment of deduced amino acids for three $D$. v. virgifera CYP4 gene fragments (CYP4AJ1, CYP4G18 and CY$P 4 A K 1)$ with three homologous CYP4 fragments from $T$. cacoeciae (CYP4G12), $H$. armigera (CYP4G8), and D. punctata (CYP4C4). Consensus sequence is provided at bottom (blackened residues are identical to consensus; periods = no consensus). Hyphens indicate gaps inserted by GCG-pileup program for alignment purposes. Amino acid residue numbers beginning at the 3 ' termini of the forward primer (i.e. conserved $i$-helix) are indicated at the left margin. The consensus sequences of the conserved motifs 'ETLR' and 'PDNF' are enclosed in boxes, and an arrow $(\downarrow)$ appears above the position of the intron found in the genomic sequence of CYP4AJ1.
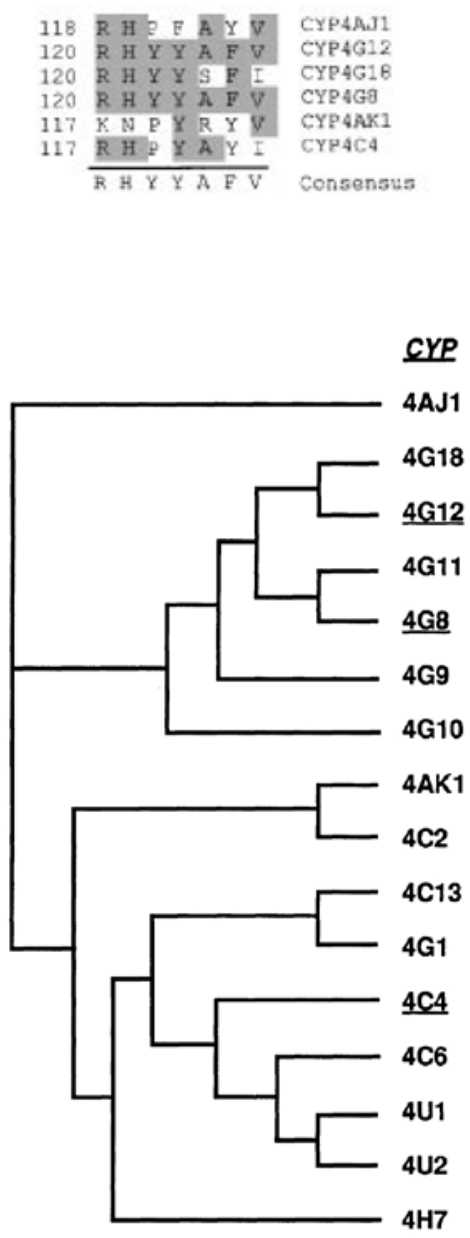

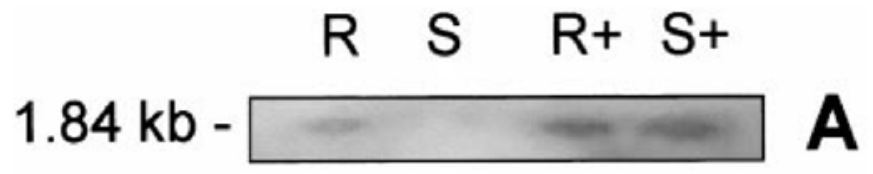

$\begin{array}{cc}\text { Genus } & \text { Accession No. } \\ \text { Dlabrotica } & \text { AF243507 } \\ \text { Diabrotica } & \text { AF243506 } \\ \text { Trichogramma } & \text { AF207949 } \\ \text { Apis } & \text { AF207948 } \\ \text { Hellcoverpa } & \text { AAD33078 } \\ \text { Helicoverpa } & \text { AAD33077 } \\ \text { Helicoverpa } & \text { AAD33079 } \\ \text { Diabrotica } & \text { AF257100 } \\ \text { Anopheles } & \text { L38671 } \\ \text { Mastotermes } & \text { AF067633 } \\ \text { Drosophila } & \text { S70623 } \\ \text { Diploptera } & \text { AF071073 } \\ \text { Diploptera } & \text { AF071075 } \\ \text { Coptotermes } & \text { AF046010 } \\ \text { Coptotermes } & \text { AAC03112 } \\ \text { Anopheles } & \text { PC2267 }\end{array}$
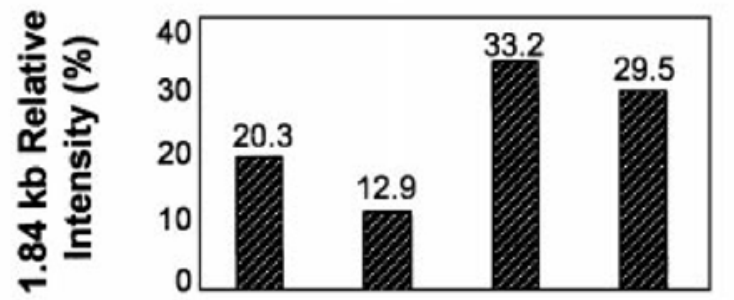

B
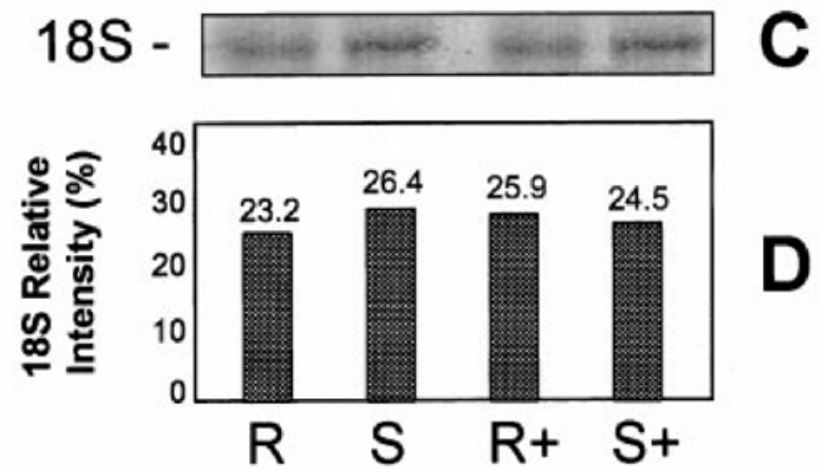

$D$

Figure 4. Northern analysis of collective CYP4 expression in insecticide-resistant and susceptible $D$. $v$. virgifera populations. Nylon membranes, containing $1.0 \mu \mathrm{g}$ of mRNA per lane, were simultaneously probed with DIG-labelled oligonucleotides corresponding to the three rootworm CYP4 gene fragments CYP4AJ1, CYP4G18 and CYP4AK1. (A) Autoradiogram showing probe hybridization to $1.84 \mathrm{~kb}$ mRNA band. (B) Densitometric data corresponding to autoradiogram shown in A. (C) Methylene blue-stained 18S RNA on membrane prior to northern hybridization. (D) Densitometric data corresponding to staining intensity shown in C. Abbreviations: $\mathrm{R}=$ resistant York population; $\mathrm{S}=$ susceptible Saunders population; + = ingeston of P450-inducer pentamethyl benzene for $96 \mathrm{~h}$ prior to mRNA isolation. 
increased 1.6- and 2.3-fold in resistant and susceptible transcripts, respectively. The resistant/susceptible ratio of intensity after PMB ingestion was 1.1-fold, indicating similar transcript levels after induction.

\section{Discussion}

CYP4 expression and induction Northern blotting experiments suggested a 1.6-fold increase in CYP4 expression levels in the insecticide-resistant York population.This result corresponds to differences in haemoprotein composition noted previously in these populations (Scharf et al., 2000b). Because the probes used for northern blotting were cloned from reverse-transcribed CDNA, it is possible but not likely that the gene fragments they represent are portions of pseudogenes. It is not clear which of the three rootworm CYP transcripts (or all) are present in increased abundance in the resistant population. It may also be possible that probes have hybridized with CYP4 transcripts other than those cloned here, however this approach may prove important for assessment of the resistance potential in rootworm populations. The closely related CYP4G8 (73\% identical to CYP4G18) was 2.4-fold over-expressed in comparisons of pyrethroid-resistant and susceptible $\mathrm{H}$. armigera (Pittendrigh et al., 1997). Other resistance-associated CYP6 and CYP9 transcripts have been found expressed at much higher magnitudes in resistant, relative to susceptible, insect populations. For example, $M$. domestica CYP6D1 and CYP6A1 transcripts were 9- and > 10-fold increased (Liu \& Scott, 1996; Cariño et al., 1994) and H. virescens CYP9A1 transcripts were 21-29-fold increased among different resistant strains (Rose et al., 1997).

Bioassays suggest the York population was not homogeneous with respect to resistance, and true differences in CYP4 expression may therefore be attenuated, particularly with respect to carbaryl metabolism where P450based $\mathrm{N}$-demethylation is most important to resistance (Scharf et al., 1999b, 2000b). More detailed investigations comparing expression of each of the three rootworm CYP4 genes individually in populations with carbaryl susceptibility would provide useful insight. Nonetheless, this information corroborates the biochemical and metabolism-based evidence previously reported for the resistant York population (Scharf et al., 1999b, 2000b).

Following ingestion of the P450 inducer PMB, CYP4 transcript levels were induced 1.6- and 2.3-fold, in resistant and susceptible rootworms, respectively. Following induction, CYP4 expression levels were more similar between populations than prior to induction. This result is consistent with PMB-induction of haemoprotein expression in rootworm microsomes (Scharf et al., 2000b). Terriere (1984) proposed that both constitutive over-expression leading to biochemical resistance and induction may be mediated by the same regulatory genes (Liu \& Scott, 1997). Genetic evidence supporting Ter- riere's hypothesis has been elucidated by studies that link housefly CYP6D1 over-expression and induction (by phenobarbital) to autosome II (Liu \& Scott, 1997). Similar evidence was presented by Cariño et al. (1994), which also linked CYP6A1 over-expression in resistant houseflies to autosome II. Housefly autosome II does not contain the structural CYP6D1 or $6 A 1$ genes, supporting that modified regulatory elements are involved in increased expression of these P450 proteins. At the present time, the constitutively greater CYP4 expression in resistant rootworms and greater degree of induction in susceptible individuals are consistent with the hypothesis that induction and over-expression are mediated by a related mechanism(s).

\section{CYP4 diversity}

The level of CYP4 diversity observed in western corn rootworms was less than noted previously in other insect species. Studies examining CYP4-P450 gene diversity within individual insect species have uncovered numerous unique forms: seventeen in Anopheles albimanus (Scott et al., 1994), seven in Manduca sexta (Snyder et al., 1995), seven in Drosophila melanogaster (Dunkov et al., 1996), and eight in Helicoverpa armigera (Pittendrigh et al., 1997). Perhaps the most compelling example of total P450 diversity in insects has come from the $D$. melanogaster genome sequencing project, where eighty-six putative CYP genes were identified with $\approx 33 \%$ belonging to family 4 (Adams et al., 2000). As reported here, only three rootworm CYP4 genes were identified. However, these three CYP genes are the first to be identified from the genus Diabrotica and the family Chrysomelidae. This information is therefore important because of (i) the absence of cloned CYP genes from the Chrysomelids, (ii) the impact of the western corn rootworm as an economic pest, and (iii) the development of wide-spread insecticide resistance in the species on multiple occasions (Metcalf, 1983; Meinke et al., 1998). It is possible, but not likely that the CYP4 diversity identified in other insect groups is absent in D. v. virgifera. Alternatively, the lack of CYP4 diversity we encountered may be related to experimental approaches. In this regard, three possibilities for improvement bear noting. First, the forward and reverse primers used here were only 8 - and 72-fold degenerate, respectively. Other primers with higher degeneracy and proven success are available (e.g. Snyder et al., 1996). Further attempts to conduct RT-PCR under varying conditions (i.e. following induction or insecticide selection) may allow amplification of more diverse CYP4 species.

\section{Conclusions}

This study was undertaken so that potential CYP4 diversity could be sampled and related expression levels compared in insecticide-resistant vs. -susceptible west- 
ern corn rootworm populations. Our primary goal in undertaking these studies was to identify resistance-associated differences between rootworm populations that could serve as molecular markers. Findings described here did not identify resistance- or susceptibility-associated sequence variation. As a result, we focused on northern blot analyses to compare collective CYP4 expression levels between resistant and susceptible populations, before and after induction. Because differences in transcript levels were inducible, and because CYP over-expression in general appears to be mediated by gene regulation (Liu \& Scott, 1997; Dunkov et al., 1997), it is unlikely that gene amplification is responsible for the resistance-associated elevation for CYP4 transcripts levels identified here.

\section{Experimental procedures}

\section{Insect populations}

Standard susceptible (Saunders) and resistant (York) populations were collected during the 1999 growing season from established collection sites. Beetles collected from these sites have been well-characterized for insecticide susceptibility (Meinke et al., 1998; Miota et al., 1998; Scharf et al., 1999a) and monooxygenase activities that correspond with resistance status (Miota et al., 1998; Scharf et al., 1999b, 2000a). Bioassays were conducted as described below to confirm the susceptibility status of these populations. Except for induction experiments (see below), beetles were maintained in the laboratory in plastic cages at 25$27^{\circ} \mathrm{C}$ using a $14: 10 \mathrm{~h}(\mathrm{~L}: \mathrm{D})$ photoperiod, on a corn ear diet, with $1 \%$ agar provided as an additional water source.

\section{Insecticide bioassays}

Bioassays were conducted in $20-\mathrm{ml}$ glass scintillation vials containing diagnostic concentrations of methyl parathion $(0.5 \mu \mathrm{g} /$ vial; L.J. Meinke, unpublished results) and carbaryl $(2.5 \mu \mathrm{g} / \mathrm{vial}$; Scharf et al., 1999a). Insecticide dilutions were prepared in acetone using technical insecticides of $>99 \%$ purity. Vials were treated with $0.5 \mathrm{ml}$ of insecticide dilution and rolled until dry in a fume hood. For each population and insecticide, ten beetles of both sexes were placed in ten replicate vials (plus two acetone control vials). Vials containing beetles were held at $22{ }^{\circ} \mathrm{C}$ in darkness for $4 \mathrm{~h}$ (methyl parathion) or $24 \mathrm{~h}$ (carbaryl) before mortality was scored as a lack of movement by the beetles.

\section{Nucleic acid isolation}

All nucleic acid extractions were from beetles held at $-80{ }^{\circ} \mathrm{C}$ for 1 week to 4 months. Genomic DNA was isolated from individual whole beetles by homogenizing in $350 \mu \mathrm{l} 1 \mathrm{~m}$ Tris, $5 \mathrm{~m} \mathrm{NaCl}$ and $5 \times 10^{-4} \mathrm{M}$ EDTA containing $70 \mu \mathrm{g}$ proteinase $\mathrm{K}$ (Sigma) and $10 \mu \mathrm{g}$ RNase A (Sigma) followed by incubation for $30 \mathrm{~min}$ at 65 ${ }^{\circ} \mathrm{C}$. Two phenol:chloroform partitioning steps (Sambrook et al., 1989) were used, and the DNA pellets from ten individuals were dissolved in Tris-EDTA ( $\mathrm{pH}$ 8.0). Total RNA for RT-PCR was isolated using the RNeasy kit (Qiagen; Valencia, CA) following the manufacturer's instructions with two beetles per isolation. mRNA for northern blotting experiments was isolated from pairs of rootworm abdomens using a Perkin-Elmer mRNA isolation kit (Fos- ter City, CA) following the manufacturer's instructions. RNA pellets were dissolved in RNase-free water, and RNA from six to ten individuals was pooled for northern blot analysis. Nucleic acids were quantified by spectrophotometry and had 260/280 nm absorbance ratios $>1.8$ (Sambrook et al., 1989).

\section{PCR, cloning, and sequence analysis}

PCR and RT-PCR were conducted using genomic DNA and reverse-transcribed 1st-strand cDNA (respectively) as templates using the 'Set B' family 4-specific primers reported by Snyder et al. (1996). Degenerate forward and reverse primers, respectively, corresponding to the i-helix and heme-binding regions of family 4 P450s were used [5'-GAG GTI GA(TC) ACI TTC ATG TTC GA(AG) GGI CAC GA(TC) AC-3' and 5'-CTG ICC GAT (AG)CA GTT ICG (GCT)GG ICC IGC (GC)I(AT) GAA (GCT)GG3']. Amplification conditions were identical to those recommended by Snyder et al. (1996), except that five cycles employing a 45 ${ }^{\circ} \mathrm{C}$ annealing temperature were used prior to thirty cycles which employed a $55{ }^{\circ} \mathrm{C}$ annealing temperature. First strand cDNA for use in RT-PCR was reverse-transcribed from total RNA using a GeneAmp RNA PCR kit following the manufacturer's instructions (Perkin Elmer; Foster City, CA) and the set B forward primer indicated above. PCR and RT-PCR products were viewed on $1 \%$ ethidium bromide-stained agarose gels. Products of the expected size $(\approx 0.40-0.55 \mathrm{~kb})$ were excised and purified using a Sephaglas BandPrep kit (Amersham Pharmacia Biotech; Piscataway, NJ). Purified PCR products were sequenced in both directions by Geneseek Inc. (Lincoln, NE) following ligation into pCR 2.1 TOPO ${ }^{\circledR}$ plasmids (Invitrogen; Carlsbad, CA) and transformation of TOP $10^{\circledR}$ competent cells (Invitrogen). Clones for sequencing were chosen based on the presence of correctsized inserts following isolation and ECoR1 digestion of recombinant plasmid DNA (Sambrook et al., 1989). Primary sequence confirmation and amino acid translations were performed using the GCG10 software package (Genetics Computer Group; Madison, $\mathrm{WI}$ ), and minor sequence discrepancies between clones were resolved by consultation of electropherograms.

CYP gene fragments were obtained using degenerate primers, therefore all sequence analyses were performed on portions of CYP4 genes excluding their highly conserved priming sites (i.e. i-helix and heme-binding regions). Pair-wise sequence analyses were performed with GCG10, using the 'GAP' function (gapweight $=50$, lengthweight $=3$ ). Multiple alignments were performed using GCG10/PILEUP (gapweight $=8$, lengthweight $=2$ ). Phylogenetic analyses were performed similarly to Snyder et al. (1995) using 'PAUP' in GCG10 under default settings, assuming maximum parsimony.

\section{P450 induction and northern analyses}

Groups of twenty-five rootworm adults were isolated from lab colonies and confined with one of the following treatments: (i) corn as a control, or (ii) $0.2 \% \mathrm{w} / \mathrm{v}$ of the P450 inducer pentamethyl benzene (PMB, Aldrich; Milwaukee, $\mathrm{WI}$ ) in water. This concentration of PMB was previously shown to effectively induce rootworm haemoprotein expression (Scharf et al., 2000b). After $96 \mathrm{~h}$, beetles were snap frozen and abdominal mRNA extracted as described above. Northern analysis probes were synthesized from 'mixed' templates corresponding to each of the three cloned and sequenced CYP4 gene fragments amplified from 1st strand cDNA by RT-PCR (i.e. CYP4AJ1, CYP4G18 and CYP4AK1). Clones used for template amplification by PCR were 
those verified by sequencing to contain respective P450 gene fragments. Probes were random labelled with digoxigenin-conjugated dUTP using the DIG High Prime Labelling Kit (Roche Biochemical; Mannheim, Germany), and exceeded the 3.0 pg quantity recommended by the manufacturer. Northern blotting was performed on RNA affixed to nylon membranes (Zeta-Probe; Bio-Rad, Hercules, CA) by capillary transfer following denaturing formaldehyde agarose electrophoresis (Sambrook et al., 1989). Hybridization occurred for $3 \mathrm{~h}$ at $48{ }^{\circ} \mathrm{C}$ and washes were of reduced stringency (i.e. two washes were at room temperature and the final wash occurred at $37^{\circ} \mathrm{C}$ with mild agitation). Luminescent detection was accomplished using the DIG High Prime Detection Kit (Roche) following the manufacturer's instructions. mRNA for use in blotting experiments was quantified spectrophotometrically and standardized loadings were confirmed prior to probe hybridization by methylene blue staining intensity of 18S RNA directly on nylon membranes (Herrin \& Schmidt, 1988). Densitometric scanning was accomplished using a GelDoc $2000 \AA$ interfaced with Quantity One $₫$ software (Bio-Rad).

\section{Acknowledgements}

The contributions of Valerie Lackey (technical assistance in molecular studies) and Jim Brown (beetle collections and colony maintenance) are gratefully acknowledged. Appreciation is also extended to Dr. David Nelson (University of Tennessee-Memphis) for assistance in naming genes and for helpful discussion, and Drs. David Taylor and Ken Pruess for manuscript review. This research was supported by USDA-ARS Specific Cooperative Agreement 58-5447-6-116. This is paper no. 13099 of the Journal Series of the University of Nebraska Agricultural Research Division and Contribution no. 1079 of the Department of Entomology, University of Nebraska-Lincoln.

\section{References}

Adams, M.D., Consortium (2000) The genome sequence of Drosophila melanogaster. Science 287: 2185-2195.

Andersen, J.F., Utermohlen, J.G., and Feyereisen, R. (1994) Expression of housefly CYP6A1 and NADPH-cytochrome $P 450$ reductase in $E$. coli and reconstitution of an insecticide-metabolizing P450 system. Biochemistry 33: 2171-2177.

Cariño, F., Koehner, J., Plapp, F.W. Jr, and Feyereisen, R. (1994) Constitutive overexpression of the cytochrome P450 gene CYP6A1 in a house fly strain with metabolic resistance to insecticides. Insect Biochem Mol Biol 24: 411-418.

Dunkov, B.C., Guzov, V.M., Mocelin, G., Shotkoski, F., Brun, A., Amichot, M., ffrench-Constant, R.H., and Feyereisen, R. (1997) The Drosophila cytochrome P450 gene Cyp6a2: structure, localization, heterologous expression, and induction by phenobarbital. DNA Cell Biol 16: 1345-1356.

Dunkov, B.C., Rodriguez-Arnaiz, R., Pittendrigh, B., ffrench-Constant, R.H., and Feyereisen, R. (1996) Cytochrome P450 gene clusters in Drosophila melanogaster. Mol Gen Genet 251: 290-297.

Feyereisen, R. (1999) Insect P450 enzymes. Annu Rev Entomol 44: 507-533.
Herrin, D.L. and Schmidt, G.W. (1988) Rapid, reversible staining of northern blots prior to hybridization. Biotechniques 6: 196-200.

Hodgson, E. (1985) Microsomal monooxygenases. In: Comprehensive Insect Physiology, Biochemistry, and Pharmacology, Vol. 11 Pharmacology (Kerkut, G.A. and Gilbert, L.I., eds), pp. 225-322. Pergammon, Elmsford, NY.

Kasai, S., Weerashinghe, I., Shono, T., and Yamakawa, M. (2000) Molecular cloning, nucleotide sequence and gene expression of a cytochrome P450 (CYP6F1) from the pyrethroid-resistant mosquito, Culex quinquefasciatus. Insect Biochem Mol Biol 30: 163-171.

Levine, E. and Oloumi-Sadeghi, H. (1991) Management of Diabroticite rootworms in corn. Annu Rev Entomol 36: 229-255.

Liu, N. and Scott, J.G. (1996) Genetic analysis of factors controlling high-level expression of cytochrome P450, CYP6D1, cytochrome b5, P450 reductase, and monooxygenase activities in LPR houseflies. Biochem Genet 34: 133-138.

Liu, N. and Scott, J.G. (1997) Phenobarbital induction of CYP6D1 is due to a trans-acting factor on autosome 2 in house flies. Insect Mol Biol 28: 531-535.

Liu, N. and Scott, J.G. (1998) Increased transcription of CYP6D1 causes cytochrome P450-mediated insecticide resistance in house fly. Insect Biochem Mol Biol 28: 531-535.

Meinke, L.J., Siegfried, B.D., Wright, R.J., and Chandler, L.D. (1998) Adult susceptibility of Nebraska western corn rootworm populations to selected insecticides. J Econ Entomol 91: 594-600.

Metcalf, R.L. (1983) Implications and prognosis of resistance to insecticides. In: Pest Resistance to Pesticides (Georghiou, G.P. and Saito, T., eds), pp. 703-732. Plenum Press, NY.

Miota, F., Scharf, M.E., Ono, M., Marçon, P., Meinke, L.J., Wright, R.J., Chandler, L.D., and Siegfried, B.D. (1998) Mechanisms of methyl and ethyl parathion resistance in the western corn rootworm. Pestic Biochem Physiol 61: 39-52.

Nebert, D.W. and Gonzalez, F.J. (1987) P450 genes: structure, evolution, and regulation. Annu Rev Biochem 56: 945-993.

Pittendrigh, B., Aronstein, K., Zinkovsky, E., Andreev, O., Campbell, B., Daly, J., Trowell, S., and ffrench-Constant, R.H. (1997) Cytochrome P450 genes from Helicoverpa armigera: expression in a pyrethroid-susceptible and -resistant strain. Insect Biochem Mol Biol 27: 507-512.

Rose, R.L., Goh, D., Thompson, D.M., Verma, K.D., Heckel, D.G., Gahan, L.J., Roe, R.M., and Hodgson, E. (1997) Cytochrome P450 (CYP) 9A1 in Heliothis virescens: the first member of a new CYP family. Insect Biochem Mol Biol 27: 605-615.

Sambrook, J., Fritsch, E.F., and Maniatis, T. (1989) Molecular Cloning: A Laboratory Manual, 2nd edn. Cold Spring Harbor Laboratory Press, Cold Spring Harbor, NY.

Scharf, M.E., Meinke, L.J., Siegfried, B.D., Wright, R.J., and Chandler, L.D. (1999a) Carbaryl susceptibility, diagnostic concentration determination and synergism for U.S. populations of western corn rootworm. J Econ Entomol 92: 33-39.

Scharf, M.E., Meinke, L.J., Wright, R.J., Chandler, L.D., and Siegfried, B.D. (1999b) Metabolism of carbaryl by insecticide-resistant and -susceptible western corn rootworm populations. Pestic Biochem Physiol 63: 85-96.

Scharf, M.E. and Siegfried, B.D. (1999) Toxicity and neurophysiological effects of fipronil and fipronil-sulfone on the western corn rootworm. Arch Insect Biochem Physiol 40: 150-156. 
Scharf, M.E., Siegfried, B.D., Meinke, L.J., and Chandler, L.D. (2000a) Fipronil metabolism, oxidative sulfone formation and toxicity among organophosphate and carbamate-resistant and -susceptible western corn rootworm populations. Pest Manage Sci 56: 757-766.

Scharf, M.E., Siegfried, B.D., Meinke, L.J., Wright, R.J., and Chandler, L.D. (2000b) Cytochrome P450-mediated N-demethylation activity and induction in insecticide-resistant and -susceptible western corn rootworm populations. Pestic Biochem Physiol 67: 137-143.

Scott, J.G. (1999) Cytochromes P450 and insecticide resistance. Insect Biochem Mol Biol 29: 757-777.

Scott, J.A., Collins, F.H., and Feyereisen, R. (1994) Diversity of cytochrome P450 genes in the mosquito, Anopheles albimanus. Biochem Biophys Res Comm 205: 1452-1459.

Siegfried, B.D. and Mullin, C.A. (1990) Metabolism, penetration, and partitioning of $\left[{ }^{14} \mathrm{C}\right]$ aldrin in aldrin-resistant and susceptible corn rootworms. Pestic Biochem Physiol 36: 135-146.
Smith, F.S. and Scott, J.G. (1997) Functional expression of house fly cytochrome P450 CYP6D1 in yeast. Insect Biochem Mol Biol 27: 999-1006.

Snyder, M.J., Scott, J.A., Andersen, J.F., and Feyereisen, R. (1996) Sampling P450 diversity by cloning polymerase chain reaction products obtained with degenerate primers. Meth Enzymol 272 304-312.

Snyder, M.J., Stevens, J.L., Andersen, J.F. and Feyereisen, R. (1995) Expression of cytochrome P450 genes of the CYP4 family in midgut and fat body of the tobacco hornworm, Manduca sexta. Arch Biochem Biophys 321: 13-20.

Terriere, L.C. (1984) Induction of detoxification enzymes in insects. Annu Rev Entomol 29: 71-88. 